\title{
Učestalost varijantne translokacije kod pacijenata s novodijagnosticiranom kroničnom mijeloičnom leukemijom (KML) u hrvatskoj populaciji
}

\section{The frequency of variant translocation in patients with newly diagnosed chronic myeloid leukemia (CML) in Croatian population}

\author{
Željka Tkalčić Švabek ${ }^{1 *}$, Marina Josipović2 ${ }^{2}$ Ivana Franić Šimić ${ }^{1}$
}

\begin{abstract}
Sažetak. Cilj: Obilježje kronične mijeloične leukemije (KML) je hibridni BCR-ABL gen nastao kao posljedica recipročne translokacije između kromosoma 9 i 22, čime se stvara Philadelphia (Ph) kromosom. Klasičnu translokaciju t(9;22) ima $90 \%$ pacijenata, dok ostalih $5-10 \%$ ima varijantnu translokaciju koja uključuje više kromosoma, izuzev kromosoma 9 i 22 . Cilj ovog istraživanja je odrediti postotak pacijenata $\mathrm{s}$ novodijagnosticiranim KML-om koji imaju varijantnu translokaciju te postotak kompletnog citogenetičkog odgovora (KCgO) pacijenata s varijantnom translokacijom u usporedbi s pacijentima koji imaju klasičnu t(9;22). Materijali i metode: $\mathrm{U}$ istraživanje je uključena koštana srž (KS) 177 pacijenata s novodijagnosticiranim KML-om. Za analizu Ph kromosoma koristio se kariogram kao klasična citogenetska analiza i fluorescentna in situ hibridizacija (FISH) kao molekularna citogenetska analiza. Rezultati: Varijantna translokacija dokazana je kod 14 pacijenata u razdoblju od 5 godina i 3 mjeseca, dok 163 pacijenta ima klasičnu translokaciju t(9;22). Zaključak: Postotak pacijenata s varijantnom translokacijom $u$ istraživanju slaže se $s$ rezultatima istraživanja u svijetu. Ne postoji statistički značajna razlika u postizanju KCgO-a kod pacijenata $s$ varijantnom translokacijom t(9;22) u usporedbi s KCgO-om pacijenata s klasičnom translokacijom.
\end{abstract}

Ključne riječi: citogenetika; koštana srž; kronična mijeloična leukemija; Philadelphia kromosom

Abstract. Aim: Chronic myeloid leukemia (CML) is characterized by a fusion of the BCR-ABL gene as the result of a reciprocal translocation of chromosomes 9 and 22 forming the Philadelphia ( $\mathrm{Ph}$ ) chromosome .Ninety percent of patients have reciprocal translocation $t(9 ; 22)$, while the other $5-10 \%$ have a variant translocation that includes more chromosomes except chromosome 9 and 22. The aim of this study is to analyze the percentage of variant translocation of newly diagnosed patients with $\mathrm{CML}$ and the percentage of total cytogenetic response $(\mathrm{KCgO})$ compared with patients having reciprocal $\mathrm{t}(9 ; 22)$. Materials and Methods: The study included bone marrow (BM) of 177 patients with newly diagnosed CML. For analysis of $\mathrm{Ph}$ chromosome, a karyogram was used as a conventional cytogenetic analysis and fluorescence in situ hybridization (FISH) as a molecular cytogenetic analysis. Results: Variant translocation has been shown in 14 patients in the period of 5 years and 3 months period, while 163 patients have reciprocal translocation $\mathrm{t}(9 ; 22)$. Conclusion: The percentage of patients with variant translocation in this study agrees with the results of research in the world. There is no statistically significant difference in achieving $\mathrm{KCgO}$ in patients with a variant translocation $\mathrm{t}(9 ; 22)$ compared to $\mathrm{KCgO}$ patients with reciprocal translocation.

Key words: bone marrow; chronic myelogenus leukemia; cytogenetics; Philadelphia chromosome

\begin{abstract}
${ }^{1}$ Klinički bolnički centar Zagreb, Klinički zavod za laboratorijsku dijagnostiku, Odjel za citogenetiku, Zagreb

2Opća bolnica „Dr. Josip Benčević” Slavonski Brod, Odjel za laboratorijsku dijagnostiku, Slavonski brod
\end{abstract}




\section{UVOD}

Karakteristika kronične mijeloične leukemije (KML) derivirani je kromosom 22(der(22)) nazvan Philadelphia (Ph) kromosom, nastao kao posljedica recipročne translokacije dugih krakova kromosoma 9 i $22 \mathrm{t}(9 ; 22)(q 34 ; q 11.2)^{1}$. Na Ph kromosomu nalazi se breakpoint cluster region-abelson (BCR-ABL) fuzijski onkogen odgovoran za nakupljanje zrelih stanica mijeloidne loze i fenotip KML-e, prisutan u $90 \%$ pacijenata ${ }^{2-3}$. Ipak, kod $5-8 \%$ novodijagno-

Kod 5 - $10 \%$ novodijagnosticiranih pacijenata s KML-om prisutna je varijantna translokacija koja uz kromosome 9 i 22 uključuje još jedan, dva, tri, četiri, čak i pet kromosoma.

sticiranih pacijenata s KML-om prisutna je varijantna translokacija koja uz 9 i 22 uključuje još jedan ili više kromosoma 4 .

Cilj ovog retrospektivnog istraživanja je odrediti postotak pacijenata $s$ novodijagnosticiranim KML-om Odjela za citogenetiku Kliničkog bolničkog centra Zagreb koji sadrže varijantnu translokaciju $t(9 ; 22)$. Usporedilo se i u kojem postotku je postignut kompletan citogenetički odgovor ( $\mathrm{KCgO}$ ) pacijenata s varijantnom translokacijom u usporedbi s KCgO-om pacijenata koji imaju prisutnu klasičnu translokaciju $\mathrm{t}(9 ; 22)$.

\section{MATERIJALI I METODE}

\section{Ispitanici}

Retrospektivna studija obuhvatila je razdoblje od siječnja 2013. do ožujka 2018. (trajanje 5 godina i 3 mjeseca), te je uključeno 78 (44\%) žena i 99 (56 \%) muškaraca. Ispitanici predstavljaju reprezentativni uzorak hrvatske populacije, s obzirom na to da se svi uzorci koštane srži (KS) novootkrivenih KML pacijenata iz Republike Hrvatske za citogenetske metode obrađuju samo na Odjelu za citogenetiku Kliničkog bolničkog centra Zagreb. Od 177 ispitanika za potrebe ove studije odgovarala su 62 pacijenta, od kojih su $10 \mathrm{~s}$ varijantnom $\mathrm{t}(9 ; 22)$ i 52 s klasičnom $\mathrm{t}(9 ; 22)$.

\section{Klasična citogenetika}

Klasična citogenetska analiza izvedena je koristeći standardnu Giemsa tehniku pruganja (engl. G-ban- ding with Trypsin / Giemsa, GTG). Kao uzorak za analizu korišten je KS 177 pacijenata s novodijagnosticiranim KML-om u epruveti s litij-heparin antikoagulansom. Stanice KS-a kultivirane su 24 sata, potom obrađene kolhicinom i hipotoničnom otopinom, isprane i učvršćene u metanol-octenoj kiselini $(3: 1)$ te učvršćene na predmetno staklo ${ }^{5}$. Nakon GTG-pruganja analizirano je 20 metafaza svakog pacijenta na svjetlosno fluorescentnom mikroskopu (Carl Zeiss Microlmaging $\mathrm{GmbH}$, Gottingen, Germany), a kariotip je analiziran koristeći program Ikaros (MetaSystems, Heidelberg, Germany). Kariotip je objašnjen koristeći kriterije Međunarodnog sustava nomenklature u humanoj citogenetici (engl. International System for Human Cytogenetic Nomenclature, ISCN $)^{6-7}$.

\section{Molekularna citogenetika}

Fluorescentna in situ hibridizacija (FISH) izvedena je na učvršćenim stanicama KS-a na predmetnom staklu dobivenim metodom klasične citogenetike. Prema uputama proizvođača na stanice na predmetnom staklu dodaje se proba, pufer i voda u određenom omjeru. Stakla se potom stave u uređaj (HYBrite, Abbott Laboratories, IL, USA) gdje dolazi do procesa denaturacije i hibridizacije probe i DNA-a. Nakon 24 sata stakla se ispiru u posebnom detergentu, a na osušene stanice na staklu kapne se boja za pozadinsko obojenje, DNA- interkalirajuća boja 4,6-diamino-2-fenilindol (DAPI) te stavi pokrovnica.

Metodom FISH moguće je analizirati interfazne jezgre i metafaze. Kao proba koristi se Vysis LSI BCR/ABL Dual-Color Dual-Fusion (Abbott Laboratories) od siječnja 2013. godine, čime je moguće odrediti varijantnu translokaciju. Strategija dvostruke fuzije koristi probu koja obuhvaća zajedničke točke loma u ABL i BCR regijama genå ${ }^{8}$. Kod svakog pacijenta analizirano je 200 interfaznih jezgara. Za analizu se koristi svjetlosni fluorescentni mikroskop (Carl Zeiss Microlmaging $\mathrm{GmbH}$, Gottingen, Germany) pod povećanjem 1000 x koristeći imerziono ulje i optičke filtere (DAPI, zeleno, crveno i triplet-filtar kojim je moguće vidjet DAPI, crveni i zeleni signal u isto vrijeme). Snimanje i obrada slike jezgara i metafaza provedena je pomoću sustava Isis (Isis software, Altlussheim, Germany). Rezultat se izražava kao postotak Ph pozitivnih jezgara na 100 izbrojenih. 
Tablica 1. Detalji 14 pacijenata s varijantnom translokacijom t(9;22).

\begin{tabular}{|c|c|c|c|c|}
\hline $\begin{array}{c}\text { Broj } \\
\text { pacijenta }\end{array}$ & spol & dob & kariotip & $\begin{array}{c}\text { \% Ph pozitivnih } \\
\text { jezgara na FISH-u }\end{array}$ \\
\hline 1 & Ž & 34 & $46, X X, t(1 ; 9 ; 22)(p 35 ; q 34 ; q 11.2)$ & 87 \\
\hline 2 & M & 42 & 46,XY,t(9;?;22)(q34;?;q11.2) & 92 \\
\hline 3 & M & 59 & $46, X Y, t(9 ; 9 ; 22)(q 34 ; q 34 ; q 11.2)$ & 80 \\
\hline 4 & Ž & 38 & 46,XX,t(9;?;22)(q34;?;q11.2) & 58 \\
\hline 5 & Ž & 33 & $46, X X, t(9 ; ? ; 22)(q 34 ; ? ; q 11.2)$ & 86 \\
\hline 6 & Ž & 42 & 46,XX,t(9;?;22)(q34;?;q11.2) & 78 \\
\hline 7 & M & 50 & $46, X X, t(9 ; 17 ; 22)(q 34 ; q 21 ; q 11.2)$ & 77 \\
\hline 8 & M & 56 & 46,XY,t(9;?;22)(q34;?;q11.2) & 78 \\
\hline 9 & M & 26 & 46,XY,t(9;?;22)(q34;?;q11.2) & 78 \\
\hline 10 & M & 46 & ins(22;1)(q11.2;q31q32)t(1;9;12;22)(q32;q34;q13;q11.2) & 91 \\
\hline 11 & Ž & 44 & $46, X X, t(9 ; ? ; 22)(q 34 ; ? ; q 11.2)$ & 78 \\
\hline 12 & M & 60 & $46, \mathrm{XY}, \mathrm{t}(9 ; 14 ; 22)(q 34 ; q 32 ; q 11.2)$ & 95 \\
\hline 13 & M & 32 & $46, X Y, t(9 ; 17 ; 22)(q 34 ; q 21 ; q 11.2)$ & 95 \\
\hline 14 & M & 67 & 46,XY,t(9;?;22)(q34;?;q11.2) & 83 \\
\hline
\end{tabular}

Granična vrijednost (engl. cut-off) određena je metodom FISH u 20 pacijenata s dijagnozom koja nije bila povezana s KML-om i iznosi $1 \%$. Ako je udio BCR-ABL pozitivnih interfaznih stanica više od $1 \%$ svih stanica, pacijent je smatran pozitivnim na preuredbu BCR-ABL gena. Vrijeme procjene postignutog $\mathrm{KCgO}-\mathrm{a}$ je 12 mjeseci od početka korištenja terapije, a rezultat izračunat koristeći metodu Kaplan-Meier.

\section{Statistika}

Rezultati istraživanja dobiveni su metodom Kaplan-Meier i prikazani krivuljama preživljenja koje prikazuju rasap populacije u vremenu ,t". Vrijednosti $P<0.05$ smatrane su statistički značajnim. Analiza statističkih podataka napravljena je u programu MedCalc (MedCalc software, Ostend, Belgium).

\section{REZULTATI}

\section{Klasična citogenetika}

Od 14 pacijenata s varijantnom translokacijom 8 je pokazalo Ph kromosom na kariogramu bez uključenog trećeg kromosoma $\mathrm{t}(9 ; ? ; 22)(q 34 ; 11.2)$. S obzirom na to da uzorci s novodijagnosticiranim KML-om imaju visok broj leukocita, moguća je loša kvaliteta metafaza, pa zbog toga nije moguće odrediti koji kromosom sudjeluje u varijantnoj translokaciji.

Od ostalih 6 pacijenata s kariogramom, 5 pacijenata ima uključen jedan kromosom u varijantnu translokaciju. Uključeni kromosomi su 1, 9, 14 i

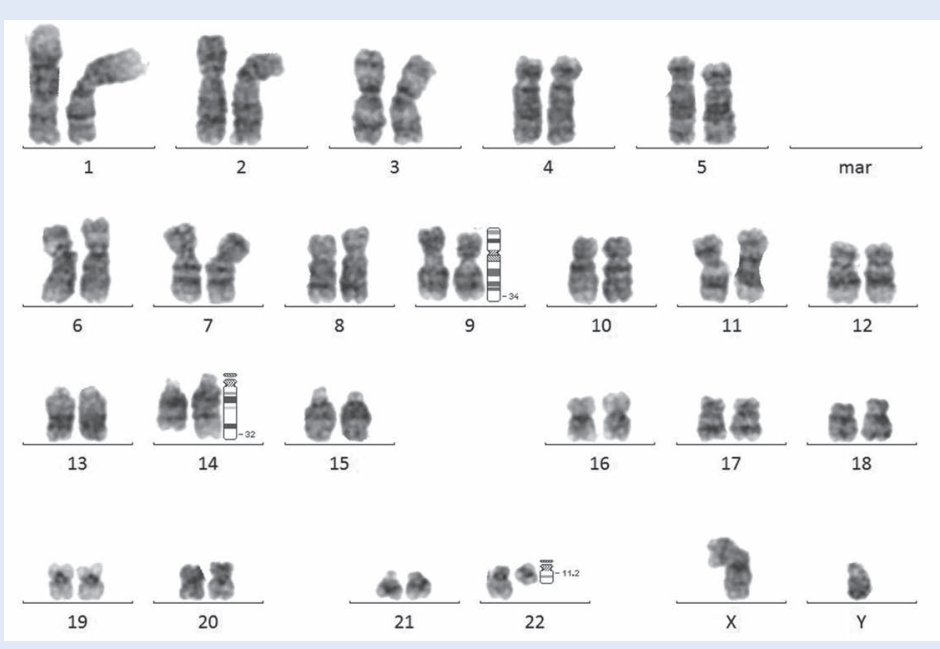

Kariogram s uključenim kromosomom 14: 46,XY,t(9;14;22)(q34;q32;q11.2)
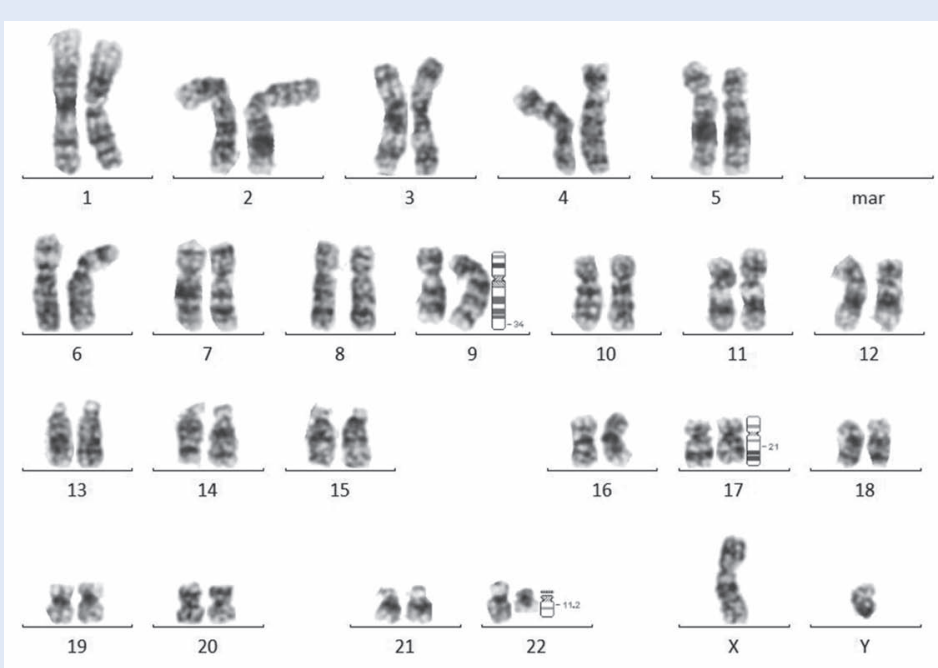

Kariogram s uključenim kromosomom 17: 46,XX,t(9;17;22)(q34;q21;q11.2)

Slika 1. 

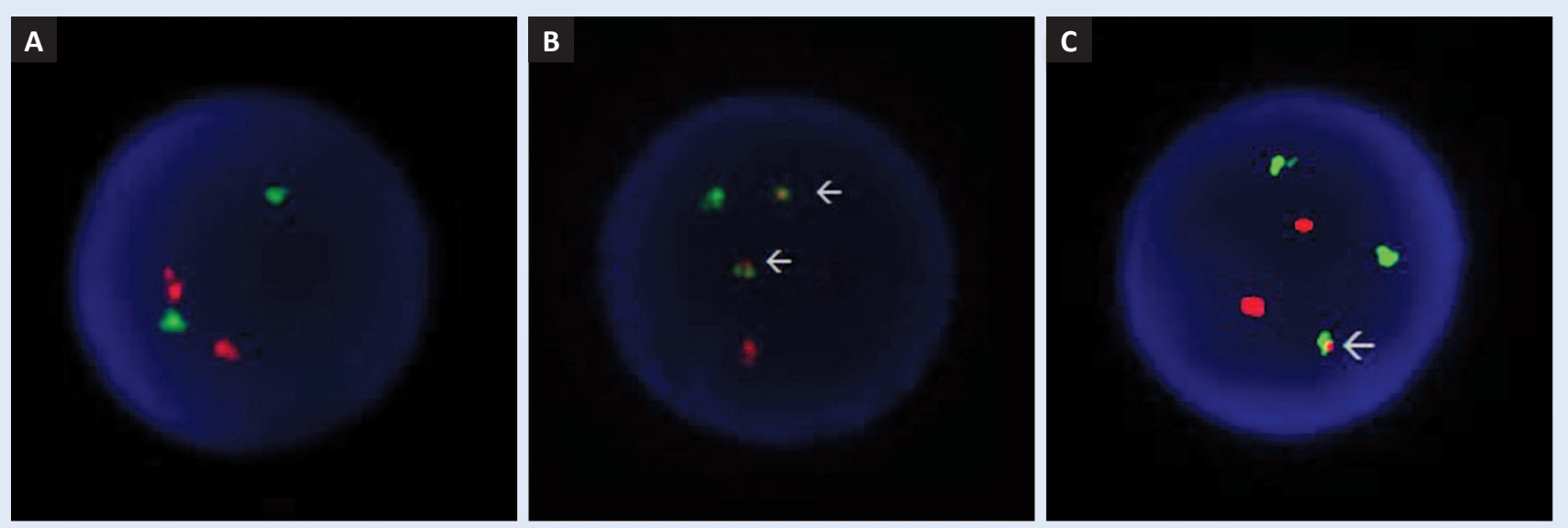

Slika 2. Signali na interfaznim jezgrama vidljivi metodom FISH: A: negativna interfazna jezgra $2 \mathrm{C} 2 Z$. B: klasična translokacija $1 \mathrm{C} 1 \mathrm{Z2} F$ (strjelicom označene dvije fuzije). C: varijantna translokacija 2C2Z1F (strjelicom označena fuzija).

17. Jedan pacijent ima dva kromosoma uključena u varijantnu translokaciju $\mathrm{i}$ to su kromosomi $1 \mathrm{i}$ 12 (tablica 1) (slika 1).

\section{Molekularna citogenetika}

Svih 177 uzoraka analizirano je FISH metodom te je potvrđena klasična ili varijantna translokacija $t(9 ; 22)$. Interfazna jezgra negativna na translokaciju t $(9,22)$ sadrži 2 crvena (ABL) i 2 zelena (BCR) signala (2C2Z). Jezgra koja sadrži klasičnu $t(9 ; 22)$ sadrži 1 crveni signal (normalan kromosom 9), 1 zeleni signal (normalan kromosom 22) i 2 žuta fuzijska signala - jedan je derivirani kromosom 22 $(\mathrm{Ph})$, a drugi derivirani kromosom 9 (der(9)) (1C1Z2F). Kod varijantne t(9;22) nalazi se samo je-

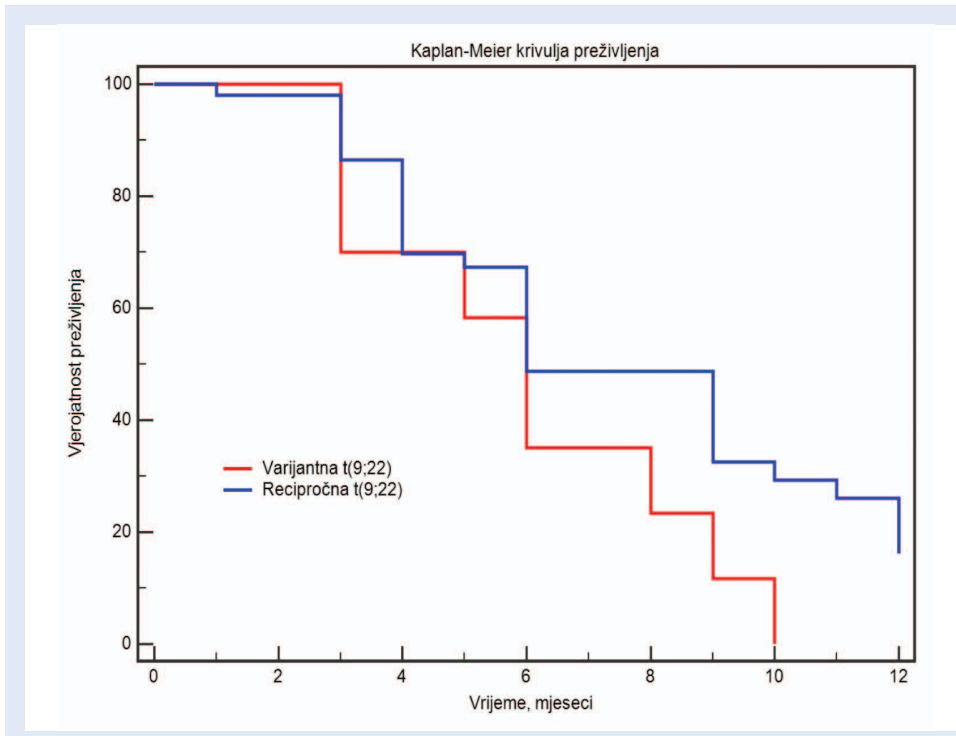

Slika 3. Kaplan-Meier krivulja preživljenja u periodu od 12 mjeseci dan žuti fuzijski signal $i$ to je derivirani kromosom 22 te 2 crvena i 2 zelena signala (1C1Z1F) (slika 2). $\mathrm{KCgO}$ je definiran kao $0 \% \mathrm{Ph}$ pozitivnih interfaznih jezgara dobivenih metodom FISH ${ }^{9}$. Po preporukama, uzorak KS-a za klasičnu citogenetsku analizu i FISH dolazi pri dijagnozi, 3 mjeseca nakon početka uzimanja terapije i potom svakih 6 mjeseci dok se ne postigne $\mathrm{KCgO}^{10}$. Unatoč preporuci, nakon dijagnoze neki pacijenti praćeni su samo metodom lančane reakcije polimeraze u realnom vremenu (engl. reverse transcription real time quantitative polymerase chain reaction, RQ-PCR). Zbog toga je $\mathrm{u}$ internoj bazi za praćenje KCgO-a manje pacijenata od ukupno novodijagnosticiranih s KML-om. Metodom Kaplan-Meier napravljena je usporedna analiza pacijenata $\mathrm{s}$ varijantnom $\mathrm{t}(9 ; 22)$ i pacijenata s klasičnom $\mathrm{t}(9 ; 22)$. $\mathrm{U}$ obje vrste $\mathrm{t}(9 ; 22)$ medijan postizanja KCgO-a iznosio je 6 mjeseci, kada je $65 \%$ pacijenata s varijantnom $t(9 ; 22)$ i $51 \%$ pacijenata s klasičnom t(9;22) postiglo KCgO. Tijekom 12 mjeseci od početka uzimanja terapije ukupno je $69 \%$ pacijenata postiglo KCgO. Usporedbom Kaplan-Meier krivulja nije dokazana statistički značajna razlika u postizanju KCgO-a kod navedenih dviju skupina pacijenata (slika 3).

\section{RASPRAVA}

Varijantnu translokaciju pokazuje $5-8 \%$ pacijenata s KML-om, što znači da je uz kromosome $9 \mathrm{i}$ 22 uključen treći, četvrti ili čak i peti kromosom ${ }^{11}$. Mehanizam varijantne translokacije nije potpuno jasan ${ }^{4}$, ali neki autori predlažu mehanizam u 1 ili 2 koraka $^{4,8}$ (slika 4). 
A

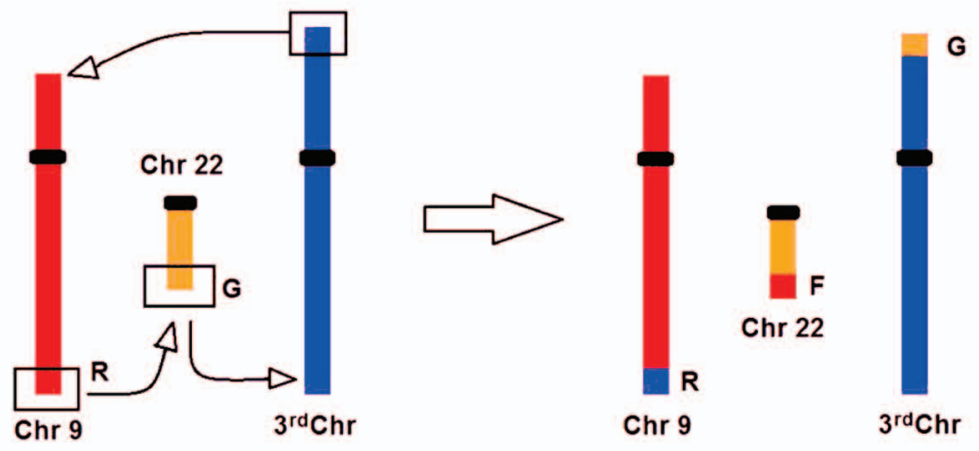

B

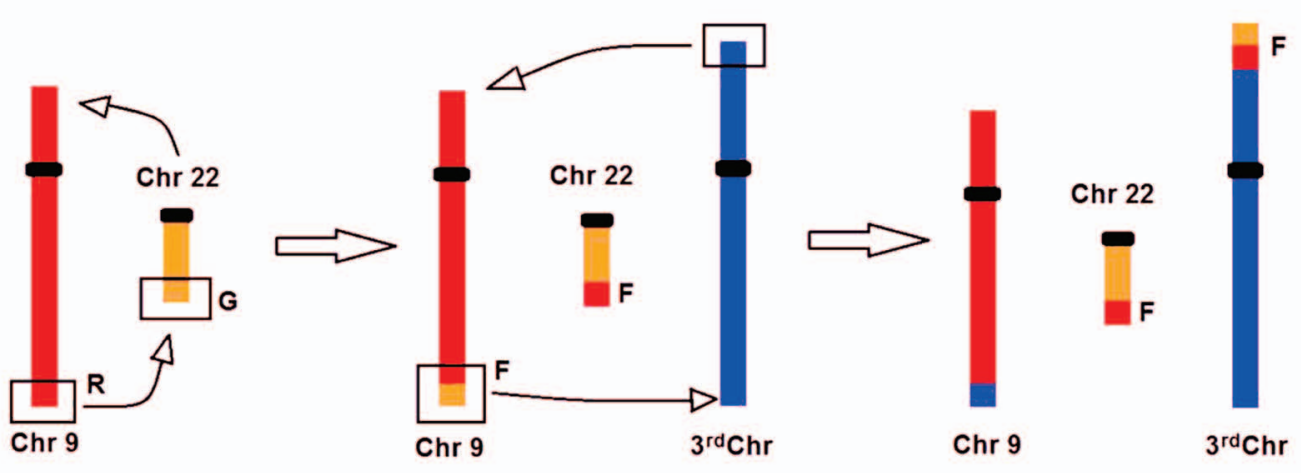

Slika 4. Mehanizam varijantne translokacije: A: mehanizam u jednom koraku u kojem se lom na kromosomima odvija istovremeno na 3 ili više različitih kromosoma. B: Mehanizam u dva koraka koji uključuje dvije uzastopne translokacije u kojoj se prvo odvija klasična translokacija $t(9 ; 22)$, a potom slijedi druga translokacija koja uključuje još jedan ili više dodatnih kromosoma.

Svi pacijenti u ovom istraživanju započeli su terapiju imatinibom (IM) u dozi od 400 miligrama (mg) dnevno. Ako odgovor na terapiju nije bio zadovoljavajući, prelazilo se na nilotinib (NI) ili dasatinib (DI).

$\mathrm{U}$ radu $8 \%$ pacijenata ima varijantnu translokaciju, što se slaže s prijavljenim istraživanjima u svije$\mathrm{tu}^{8,12-13}$. U translokaciju su uključeni kromosomi 17 u dva slučaja, te kromosomi 1, 9, 12 i 14 kod ostalih pacijenata. U praćenje postizanja KCgO-a uključeno je 10 pacijenata s varijantnom translokacijom. Devet pacijenata postiglo je KCgO tijekom 12 mjeseci praćenja te se rezultat slaže $\mathrm{s}$ rezultatima nekih istraživanja ${ }^{12-14}$.

Mnoga istraživanja pratila su prognostički značaj pacijenata $s$ varijantnom translokacijom u usporedbi s klasičnom. Nekoliko istraživanja pokazalo je lošiju prognozu pacijenata s varijantnom translokacijom. Lee i sur. naveli su sveukupno niže preživljenje kod 5-godišnjeg praćenja 22 pacijenata na terapiji IM-om s varijantnom translokacijom $^{15}$. Podatci Stango i sur. upućuju da prisutnost
Prihvaćeno je da ne postoji statistički značajna razlika u postizanju kompletnog citogenetskog odgovora među pacijentima $\mathrm{s}$ varijantnom i klasičnom Ph translokacijom. Razlike postoje u nekim istraživanjima između prognostičkog značaja pacijenata s varijantnom i klasičnom translokacijom.

varijantne translokacije pri dijagnozi može dovesti do nepovoljnog kliničkog ishoda, budući da te genetske promjene mogu biti biljezi genomske nestabilnosti i ukazivati na veću vjerojatnost napredovanja bolesti ${ }^{13}$.

El Zimaity i sur. prijavili su prvo veliko istraživanje kod pacijenata s varijantnom translokacijom liječenih IM-om ${ }^{16}$. Od 721 pacijenta s KML-om, 44 je imalo varijantnu Ph translokaciju. Jedina statistički značajna razlika je u akceleriranoj fazi bolesti, gdje je $4 \%$ pacijenata imalo klasičnu, a $9 \%$ varijantnu Ph translokaciju. Kanakasetti i sur. objavili su rad s najvećim brojem pacijenata s varijantom 
translokacijom u indijskoj populaciji ${ }^{17}$. Od 615 pacijenata, 72 su pokazala varijantnu translokaciju, dok KCgO nije bio statistički različit od pacijenata s klasičnom translokacijom. Također, u 5-godišnjem praćenju nije bilo statistički bitne razlike $u$ preživljavanju pacijenata obiju skupina. U velikoj retrospektivnoj studiji Fabarius i sur. analizirali su $1151 \mathrm{Ph}$ pozitivnog pacijenta od kojih 69 ima varijantnu translokaciju ${ }^{18}$. Zaključili su da nema značajne razlike u postizanju KCgO-a i 5-godišnjem preživljenju te napretku bolesti između pacijenata s klasičnom i varijantnom translokacijom.

Marzocchi i sur. u istraživanju koje obuhvaća 559 pacijenata, od čega $30 \mathrm{~s}$ varijantnom translokacijom, objavljuju da nema utjecaja na postizanje KCgO-a tijekom 12 mjeseci praćenja ${ }^{8}$. Stoga su predložili da pacijenti s varijantnom translokacijom ne predstavljaju posebnu kategoriju upozorenja kod pacijenata liječenih IM-om.

$U$ usporedbi sa spomenutim istraživanjima, ovaj rad ima manji broj pacijenata. Metodom Kaplan-Meier dobivena je vrijednost $P=0.091$, što pokazuje da ne postoji statistički bitna razlika u postizanju KCgO-a kod pacijenata s klasičnom i varijantnom translokacijom tijekom 12 mjeseci praćenja.

\section{ZAKLJUČAK}

Općenito je prihvaćeno da ne postoji statistički značajna razlika u postizanju $\mathrm{KCgO}-\mathrm{a}$ među pacijentima s varijantnom i klasičnom Ph translokacijom $^{8,17-19}$. Razlike postoje u nekim istraživanjima između prognostičkog značaja pacijenata s varijantnom i klasičnom translokacijom ${ }^{15-16}$. Zaključak ovog istraživanja je da ne postoji razlika u postizanju KCgO-a kod pacijenata liječenih IM-om ili NI-om u te dvije skupine pacijenata.

Izjava o sukobu interesa: Autori izjavljuju da ne postoji sukob interesa.

\section{REFERENCES}

1. Kang ZJ, Liu YF, Xu LZ, Long ZJ, Huang D, Yang Y et al. .The Philadelphia chromosome in leukemogenesis.Chin J Cancer 2016;35-48.

2. Costa D, Grau J, Espinet B, Arias A, Gómez C, Lopez-Guerra $\mathrm{M}$ et al. Conventional and molecular cytogenetic studies to characterize 32 complex variant Philadelphia translocations in patients with chronic myeloid leukemia. Oncol Lett 2019;5705-10.

3. Cilloni D, Saglio G. Molecular pathways: BCR-ABL.Clinical Cancer Research 2012;18:930-7.
4. Gorusu M, Benn P, Li Z, Fang M. On the genesis and prognosis of variant translocations in chronic myeloid leukemia. Cancer Genet Cytogenet 2007;173:97-106.

5. Rooney DE. Human cytogenetics: malignancy and acquired abnormalities. 3rd ed. Oxford, UK: Oxford University Press; 2001.

6. Shaffer LG, McGowan JJ, Schmid M. ISCN 2013: An International System for Human Cytogenetic Nomenclature. Basel, Switzerland: S. Karger; 2013.

7. McGowan-Jordan J, Simons A, Schmidt M. ISCN 2016: An International System for Human Cytogenetic Nomenclature. Basel, Switzerlan: Kagler Medical and Scientific Publishers, 2016.

8. Marzocchi G, Castagnetti F, Luatti S, Baldazzi C.Stacchini $M$, Gugliotta $G$ et al. Variant Philadelphia translocations: molecular-cytogenetic characterization and prognostic influence on frontline imatinib therapy, a GIMEMA Working Party on CML analysis. Blood 2011;117:6793-800.

9. Gadhia PK, Shastri GD, Shastri EG. Imatinib resistance and relapse in CML patients with complex chromosomal variants. American Journals of Cancer Science 2015;4:43-53.

10. Baccarani $M$, Deininger MW, Rosti $G$ et al. European LeukemiaNet recommendations for the management of chronic myeloid leukemia: 2013. Blood 2013;122:872-84.

11. Asif M, Jamal MS, Khan AR, Naseer MI, Hussain A, Choudhry H. A Novel Four-Way Complex Variant Translocation Involving Chromosome 46,XY,t(4;9;19;22) (q25:q34;p13.3;q11.2) in a Chronic Myeloid Leukemia Patient. Front Oncol 2016;30;6:124.

12. Koshiyama DB, Capra ME, Paskulin GA, Rosa RF, Oliveira $\mathrm{CA}$, Vanelli $\mathrm{T}$ et al. Cytogenetic response to imatinib treatment in Southern Brazilian patients with chronic myelogenous leukemia and variant Philadelphia chromosome. Ann Hematol. 2013;92:185-9.

13. Stagno F, Vigneri P, Del Fabro V, Stella S, Cupri A, Massimino $M$, Consoli $C$ et al. Influence of complex variant chromosomal translocations in chronic myeloid leukemia patients treated with tyrosine kinase inhibitors. Acta Oncol. 2010;49:506-8.

14. Eyüpoğlu D, .Bozkurt $S$, Haznedaroğlu I, Büyükaşık $Y$, Güven D. The Impact of Variant Philadelphia Chromosome Translocation on the Clinical Course of Chronic Myeloid Leukemia. Turk J Haematol 2016;33:60-5.

15. Lee SE, Choi SY, Bang JH, Kim SH, Jang EJ, Byeun JY et al.The long-term clinical implications of clonal chromosomal abnormalities in newly diagnosed chronic phase chronic myeloid leukemia patients treated with imatinib mesylate. Cancer Genet 2012;205:563-71.

16. El-Zimaity MM, Kantarjian H, Talpaz M, O'Brien S, Giles $F$, Garcia-Manero G, Verstovsek $S$ et al. Results of imatinib mesylate therapy in chronic myelogenous leukaemia with variant Philadelphia chromosome. Br J Haematol 2004;125:187-95.

17. Kanakasetty GB, Kuntejowdahalli L, Thanky AH, Dasappa L, Jacob LA, Mallekavu SB et al. Predictive and Prognostic Implications of Variant Philadelphia Translocations in CML: Experience From a Tertiary Oncology Center in Southern India.Clin Lymphoma Myeloma Leuk 2017;17:52-9.

18. Fabarius A, Leitner A, Hochhaus A, Müller MC, Hanfstein $B$, Haferlach C et al. Impact of additional cytogenetic aberrations at diagnosis on prognosis of CML: long-term observation of 1151 patients from the randomized $\mathrm{CML}$ Study IV. Blood 2011;118:6760-8. 